\title{
Electret Stability Related to Spherulites in Polypropylene
}

\author{
Thyssen, Anders; Almdal, Kristoffer; Thomsen, Erik Vilain
}

Published in:

IEEE Transactions on Dielectrics and Electrical Insulation

Link to article, DOI:

10.1109/TDEl.2015.004891

Publication date:

2015

Document Version

Peer reviewed version

Link back to DTU Orbit

Citation (APA):

Thyssen, A., Almdal, K., \& Thomsen, E. V. (2015). Electret Stability Related to Spherulites in Polypropylene. IEEE Transactions on Dielectrics and Electrical Insulation, 22(5), 2858-2863.

https://doi.org/10.1109/TDEl.2015.004891

\section{General rights}

Copyright and moral rights for the publications made accessible in the public portal are retained by the authors and/or other copyright owners and it is a condition of accessing publications that users recognise and abide by the legal requirements associated with these rights.

- Users may download and print one copy of any publication from the public portal for the purpose of private study or research.

- You may not further distribute the material or use it for any profit-making activity or commercial gain

- You may freely distribute the URL identifying the publication in the public portal

If you believe that this document breaches copyright please contact us providing details, and we will remove access to the work immediately and investigate your claim. 


\title{
Electret Stability Related to Spherulites in Polypropylene
}

\author{
Anders Thyssen, Kristoffer Almdal and Erik V. Thomsen \\ Technical University of Denmark \\ Department of Micro and Nanotechnology \\ Ørsteds Plads 345Ø, 2800 Kgs. Lyngby, Denmark
}

\begin{abstract}
Electret charge stability has been related to the size of the spherulites in polypropylene. As the size of the spherulites is decreased the stability is increased. This is seen for isothermal conditions at $90{ }^{\circ} \mathrm{C}$ and $120{ }^{\circ} \mathrm{C}$ as well as for $90 \%$ relative humidity at $50{ }^{\circ} \mathrm{C}$. The charge release temperature is also increased in thermally stimulated voltage discharge experiments as the size of the spherulites is decreased. The size of the spherulites is controlled though the cooling rate from polypropylenes liquid state.
\end{abstract}

Index Terms - Crystals, electrets, humidity measurement, polypropylene films, spherulite.

\section{INTRODUCTION}

Polypropylene is used for investigating the discharge mechanisms in polymer electret materials. The goal is to get an understanding of how to enhance the temperature and humidity charge stability for polypropylene and to be able to transfer this knowledge to other electret polymers. The choice of polypropylene as a model system is taking advantage of the limited charge lifetime in this system compared to other much more stable electrets, thus enabling a faster observation of performance improvements in polypropylene electrets as compared to more stable polymer electrets.

It has previously been reported that the charges in semicrystalline electret polymers are located at the center of the spherulites and at spherulictic boundaries [1]. In this article, the relation between charge stability in polypropylene electrets, and the size of the spherulites is investigated.

Through different means, one can control the size of the spherulites; the most common method is adding nucleation agents [2-4], which the plastics industry is using in large scale. However, process temperature and cooling rate also play an important role when spherulites are formed [5-7]. In this work the final size of the spherulites are controlled by the heating and cooling rates. The reason for this is that the possible influence from the nucleation agents are unwanted, at this present state of our investigation.

\section{Experimental Procedures}

This section covers the details regarding sample preparation and experimental procedures.

\subsection{Support Structure and Spin Coating}

All samples consist of a support structure and a spin coated layer of isotactic polypropylene, with a weight average molecular weight of $250,000 \mathrm{~g} / \mathrm{mol}$ and a number average molecular weight of $67,000 \mathrm{~g} / \mathrm{mol}$.

The support structures consist of a single side polished, $10 \mathrm{~cm}$ diameter, highly doped silicon wafer with a $100 \mathrm{~nm}$ thick layer of titanium on the front side. The titanium is to provide good electrical conductivity throughout the support structure and to ensure the adhesion of polypropylene to the front side. A highly doped silicon wafer as support structure has been chosen due to its very low electrical resistivity, which is below $0.025 \Omega \mathrm{cm}$, and flatness.

The polypropylene is spin coated on to the support structure, from a 10/90 wt\% polypropylene/cyclohexane solution. Prior to spin coating the solution has been heated to $120{ }^{\circ} \mathrm{C}$ under pressure for at least 18 hours to ensure complete dissolution of the polypropylene beads. Upon use, the solution is cooled to $77^{\circ} \mathrm{C}$, which is a metastable state for the solution. The time window of use, at $77{ }^{\circ} \mathrm{C}$, is approximately 1 hour, before the solution should be reheated to $120^{\circ} \mathrm{C}$, after which the solution can be reused.

The spin coating is performed in two steps both at $500 \mathrm{rpm}$, to reach a final thickness of around $30 \mu \mathrm{m}$ to $40 \mu \mathrm{m}$. The pouring of the hot polypropylene solution, onto the support substrate, is done at $250 \mathrm{rpm}$ and then accelerated to $500 \mathrm{rpm}$ for $60 \mathrm{~s}$ when the solution reaches the edge of the support substrate. After each spin coating, the samples are heat treated in an oven at $180^{\circ} \mathrm{C}$ for $2 \mathrm{~min}$., this is to ensure complete evaporation of the cyclohexane and to reduce the internal stress in polypropylene, which the spin coating has introduced.

Even though a spin coating technique is used, the surface of the samples are very rough, up to $\pm 10 \mu \mathrm{m}$, and to ensure a consistent surface morphology the samples are leveled in a press. 


\subsection{Press and Cooling}

To ensure a consistent surface morphology the samples are pressed at 10 bar and $180{ }^{\circ} \mathrm{C}$ for $5 \mathrm{~min}$. On top of the sample that is to be pressed, a silver-coated silicon wafer is placed, the silver is used as a non-adherence surface. Around the sample and the silver-coated wafer, silicon rubber sheets are used to ensure an even distribution of the pressure. The thickness of the polypropylene after this treatment is approximately $30 \mu \mathrm{m}$.

After the samples have been pressed, they are exposed to one of three cooling methods, which eventually determines the size of the spherulites: 1) Slow cooling - cooled from $180{ }^{\circ} \mathrm{C}$ to room temperature in $5 \mathrm{~min}$. 2) Medium cooling - cooled from $180{ }^{\circ} \mathrm{C}$ to room temperature in approximately 10 s. 3) Fast cooling - cooled in an ice bath, from $180{ }^{\circ} \mathrm{C}$ to $0{ }^{\circ} \mathrm{C}$ in approximately $1 \mathrm{~s}$.

\subsection{Spherulite Size}

The size of the spherulites is determined by a combination of optical reflection microscopy, Scanning Electron Microscopy (SEM), and image processing and analysis using the program ImageJ $1.48 \mathrm{v}$. For the samples, where the spherulites were visible by optical microscopy, five images were taken at different locations: center, north, south, east and west. Samples from each cooling method were also investigated in a FEI Quanta FEG 200 SEM, where enhanced sensitivity towards small spherulites was obtained. Before the SEM investigation the samples were exposed to a selective etch as described in [89]. This was done to enhance the contrast in the SEM between the amorphous and the crystalline areas. The spherulite density at the surface and the mean area of the spherulites were determined with ImageJ.

\subsection{Crystallinity}

The crystallinity of the samples was determined with a Differential Scanning Calorimeter (DSC) 4000 from Perkin Elmer. $10 \mathrm{mg}$ to $18 \mathrm{mg}$ of polypropylene was removed from the substrates for each analysis. The crystallinity stated in this work is an average of a minimum of five runs. The heating rate was $20{ }^{\circ} \mathrm{C} / \mathrm{min}$ and the crystallinity was determined from the first cycle. This was done from the ratio of the melting peak to the heat of fusion for polypropylene (207 J/g [10]).

\subsection{Charging and Surface Potential}

The samples were charged in a corona discharge setup for 2 min., the principle behind the setup is described in [11]. The distance from the needle to the grid is $3 \mathrm{~cm}$ and the distance from the grid to the sample is $3 \mathrm{~mm}$. The grid is used as a common ground for the needle and the sample, and the potential from the needle to the grid is fixed at $-10 \mathrm{kV}$ using an EMCO high voltage component "Q101N". The potential from the grid to the sample can be controlled from $0 \mathrm{~V}$ to $2000 \mathrm{~V}$ using an EMCO USB high voltage power supply "USB20P". All samples are charged to $-500 \mathrm{~V}$ and left at ambient conditions for a minimum of 12 hours before being used in any experiments. This was done because we are interested in the longtime stability of the electrets and we would like to exclude the short time decay from the experiments. There was no correlation between the size of the spherulites and the decay in the first 12 hours.
The surface potential has been measured with an electrostatic voltmeter located $1 \mathrm{~mm}$ to $2 \mathrm{~mm}$ above the surface of the samples. Two electrostatic voltmeters have been used which both were reading the same values: Isoprobe $244 \mathrm{~A}$ with probe 1017AE and Trek 347 with probe 6000B-7C.

\subsection{Isothermal Voltage Decay}

The isothermal voltage decay experiments were conducted at $90{ }^{\circ} \mathrm{C}$ and at $120{ }^{\circ} \mathrm{C}$, both for 25 hours. Each sample was measured five times in the 25 hour period and each time at five different locations similar to the areas, used for optical microscopy, where the size of the spherulites had been analyzed. At each measurement all samples were taken out of the oven and returned when all the measurements had been performed. For practical reasons the samples used for the $120{ }^{\circ} \mathrm{C}$ experiment had previously been used first for the $90{ }^{\circ} \mathrm{C}$ and then for the humidity experiment. This is acceptable because there is no phase transitions in polypropylene between room temperature and $120^{\circ} \mathrm{C}$. Furthermore the recrystallization temperature for isotactic polypropylene, coming from room temperature, is well above $120{ }^{\circ} \mathrm{C}$ [12] and the stress of the experiments are gradually increasing. The relative humidity for the isothermal experiment is expected to be below $2 \% \mathrm{RH}$.

\subsection{Humidity Voltage Decay}

The humidity induced voltage decay experiment was conducted at $50{ }^{\circ} \mathrm{C}$ and $90 \% \mathrm{RH}$ for 25 hours. The climate chamber used was a Vötsch VC 4060. Each sample was measured in the same way as the samples at the isothermal experiments. The samples used for the humidity experiment had previously been used in the isothermal $90{ }^{\circ} \mathrm{C}$ experiment.

\subsection{Thermally Stimulated Voltage Discharge}

The thermally stimulated voltage discharge experiments were conducted using a programmable hotplate, EchoTherm Model HS60, and one of the electrostatic voltmeters mentioned in section 2.5 ; e.g. open circuit. The samples were placed on a $6 \mathrm{~mm}$ thick aluminum block, with a built in temperature probe in the center of the block. The signal from the temperature probe was fed back to the hotplate. The stack was placed on top of the hotplate, and the temperature was raised, with a heating rate of $3{ }^{\circ} \mathrm{C} / \mathrm{min}$, from room temperature to $200{ }^{\circ} \mathrm{C}$. The surface potential was measured continuously throughout the experiments with the aluminum block as electrical ground.

\section{Results And Discussion}

This section covers the result from the experiments described in section 2. Unless stated otherwise, each data point is based on an average from five different measuring points from five equivalent samples. The presented data has also been normalized at $\mathrm{t}=720 \mathrm{~min}$., when the stressing of the samples began.

\subsection{Spherulite Size}

Figure 3.1a, 3.1b and 3.1c show SEM images from samples that have all been exposed to different cooling methods: slowly, medium and fast, respectively; as described in section 2.2. It is easy to see the difference in the size of the sperulites between Figure 3.1a and 3.1b, where the largest shperulites are seen in Figure 3.1a. A few of the large spherulites, on the samples that 

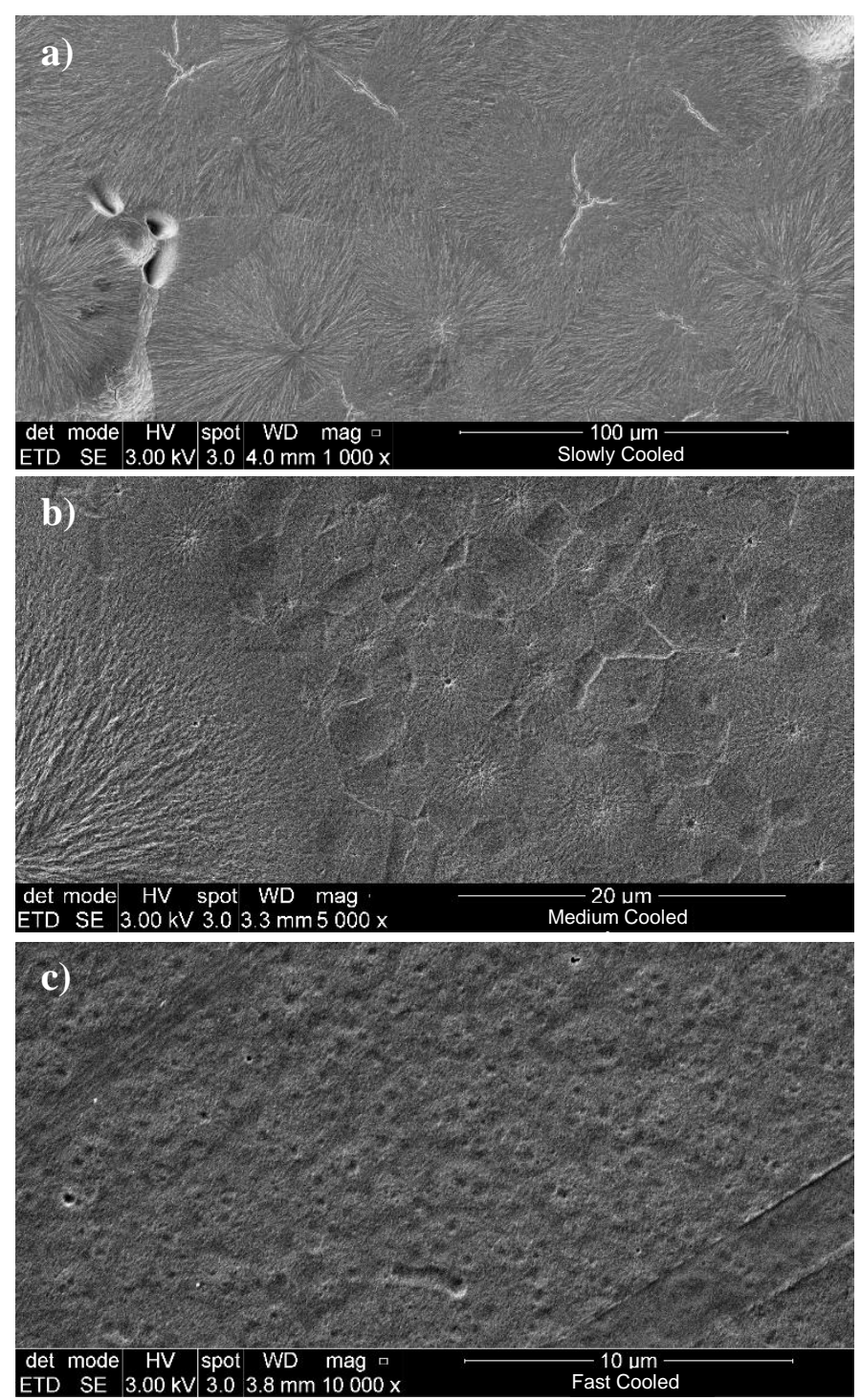

Figure 3.1 SEM Images of samples that all have been cooled at different rates, (a) slowly, (b) medium and (c) fast. The results from the data analysis is summarized in Table 3.1.

Table 3.1 Summary of the data analysis of the SEM images from the different types of samples ("Spherulite density" and "Mean spherulite area") and the degree of crystallinity from the DSC analysis ("Mean crystallinity").

\begin{tabular}{l|c|c|c}
\hline & $\begin{array}{c}\text { Slowly } \\
\text { cooled }\end{array}$ & $\begin{array}{c}\text { Medium } \\
\text { cooled }\end{array}$ & Fast cooled \\
\hline $\begin{array}{l}\text { Spherulite density } \\
\text { Mean spherulite }\end{array}$ & $10 \mathrm{k}-30 \mathrm{k} \mathrm{cm}^{-2}$ & $2 \mathrm{M}-11 \mathrm{M} \mathrm{cm}^{-2}$ & $32 \mathrm{M}-204 \mathrm{M} \mathrm{cm}^{-2}$ \\
area & $2950 \mu \mathrm{m}^{2}$ & $23 \mu \mathrm{m}^{2}$ & $1 \mu \mathrm{m}^{2}$ \\
Mean crystallinity & $49 \%$ & $43 \%$ & $41 \%$ \\
\hline
\end{tabular}

have been medium cooled, are still present, see e.g. the left corner in Figure 3.1b. In Figure 3.1c, the spherulites are harder to see, but the structures that look like craters are the center of the spherulites. The spherulites seen in Figure 3.1a and 3.1b could also be seen in the optical microscope whereas the spherulites visible in Figure 3.1c were too small to be observed.

Table 3.1 summarizes the results from the data analysis of the optical and SEM images from the different types of samples. The data for the slowly and medium cooled samples are based on a combination of both optical and SEM images, while the data for the fast cooled samples are only based on the SEM images. As seen, the density of the spherulites is increased 2-3 orders of magnitude from the slowly cooled to the medium cooled samples and additionally 1-2 orders of magnitude from the medium cooled to the fast cooled samples. The size of the spherulites also decreases drastically as the cooling rate goes up. From the slowly to the fast cooled sample the mean size of the spherulites decreases from $2950 \mu \mathrm{m}^{2}$ to $1 \mu \mathrm{m}^{2}$.

In Table 3.1, the crystallinity of the samples are also seen, and as expected, it is the slowly cooled samples that have the highest degree of crystallinity, which is $49 \%$. As the cooling rate goes up the degree of crystallinity goes down and for the fast cooled samples the crystallinity is $41 \%$.

As the radius of gyration for the polypropylene that is used is around $5 \mathrm{~nm}$ it is fair to assume that the formation of the spherulites is a bulk phenomenon; that is the formation of the spherulites takes place throughout the polypropylene film. It is therefore expected that the samples that have been cooled medium and fast have multiple layers of spherulites. For the samples that have been slowly cooled, only a single layer of spherulites is expected since the size of the spherulites, is larger than the thickness of the polypropylene film.

We note that the thermal treatment of the film that is part of the measurements $\left(25 \mathrm{~h}\right.$ at $90{ }^{\circ} \mathrm{C} ; 25 \mathrm{~h}$ at $50{ }^{\circ} \mathrm{C}, 90 \% \mathrm{RH} ; 25 \mathrm{~h}$ at $120^{\circ} \mathrm{C}$ ) does not lead to any change in the film morphology as observed in optical microscopy. We take this observation as an indication that all samples are partially crystalline and only differ in the reported difference in spherulite size and (to a small degree) in the degree of crystallinity.

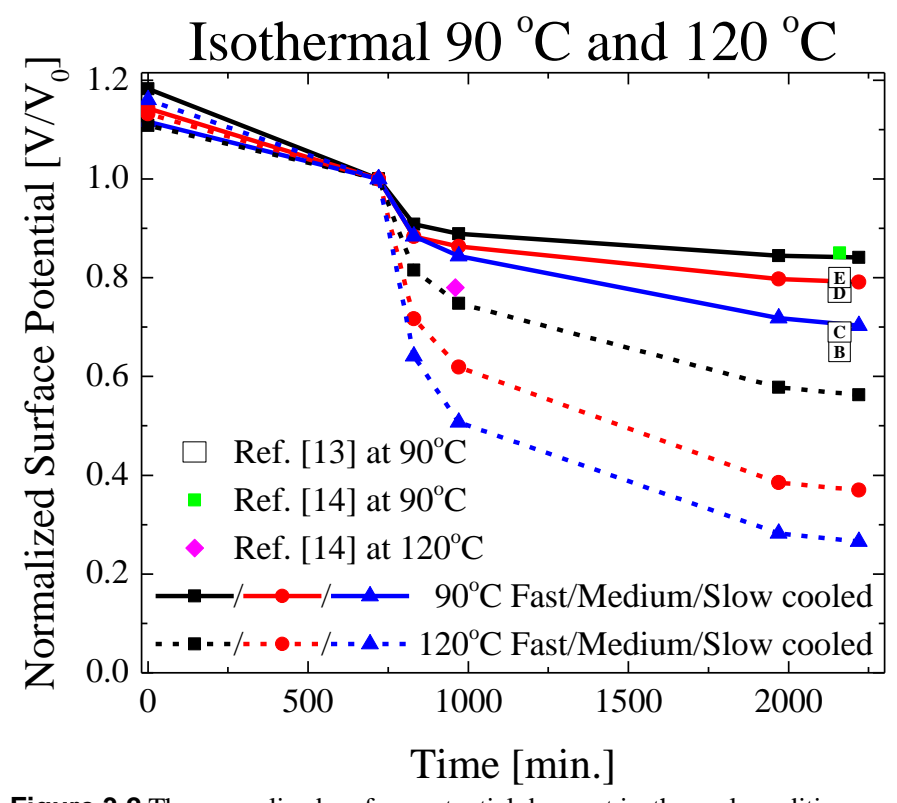

Figure 3.2 The normalized surface potential decay at isothermal conditions at $90{ }^{\circ} \mathrm{C}$ (solid lines) and $120^{\circ} \mathrm{C}$ (dashed lines) for 25 hours. The data from [13] (letters) were cooled at temperature rates $\mathrm{B}=10 \mathrm{~K} / \mathrm{min}, \mathrm{C}=10 \mathrm{~K} / \mathrm{min}$, $\mathrm{D}=235 \mathrm{~K} / \mathrm{min}$ and $\mathrm{E}=300 \mathrm{~K} / \mathrm{min}$. The data from [14] are for biaxially stretched isotactic polypropylene. The data has been normalized at $\mathrm{t}=720 \mathrm{~min}$. when the stressing of the samples began. 


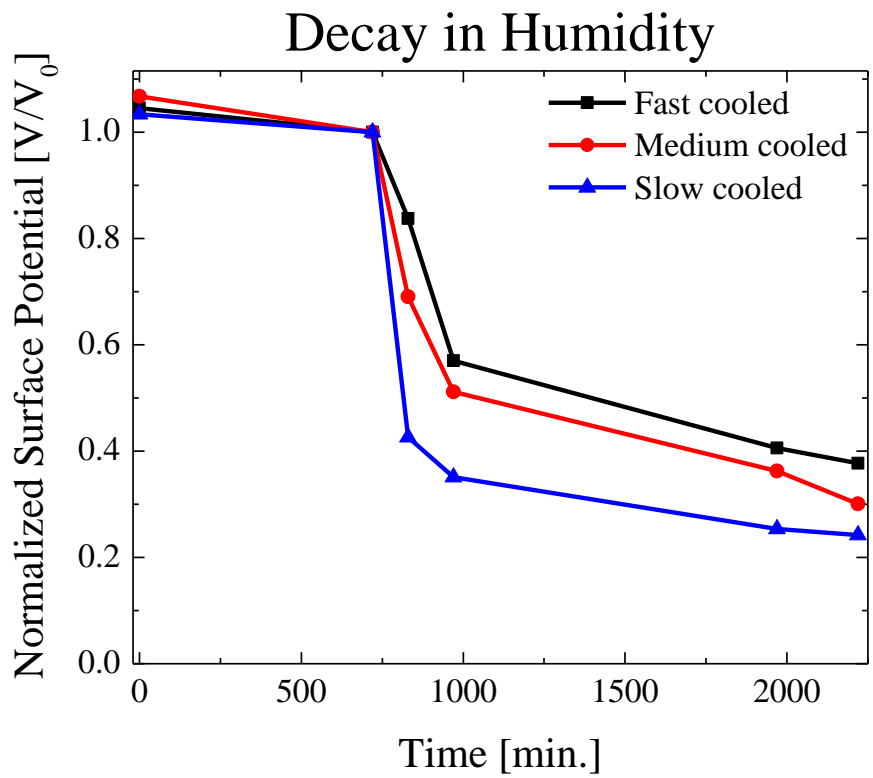

Figure 3.3 The normalized surface potential decay at $50{ }^{\circ} \mathrm{C}$ and $90 \% \mathrm{RH}$. The trend of better charge retention for samples that have been exposed to the highest cooling rate can be seen again. The data has been normalized at $t=720$ min. when the stressing of the samples began.

\section{Stability after 25 hour}

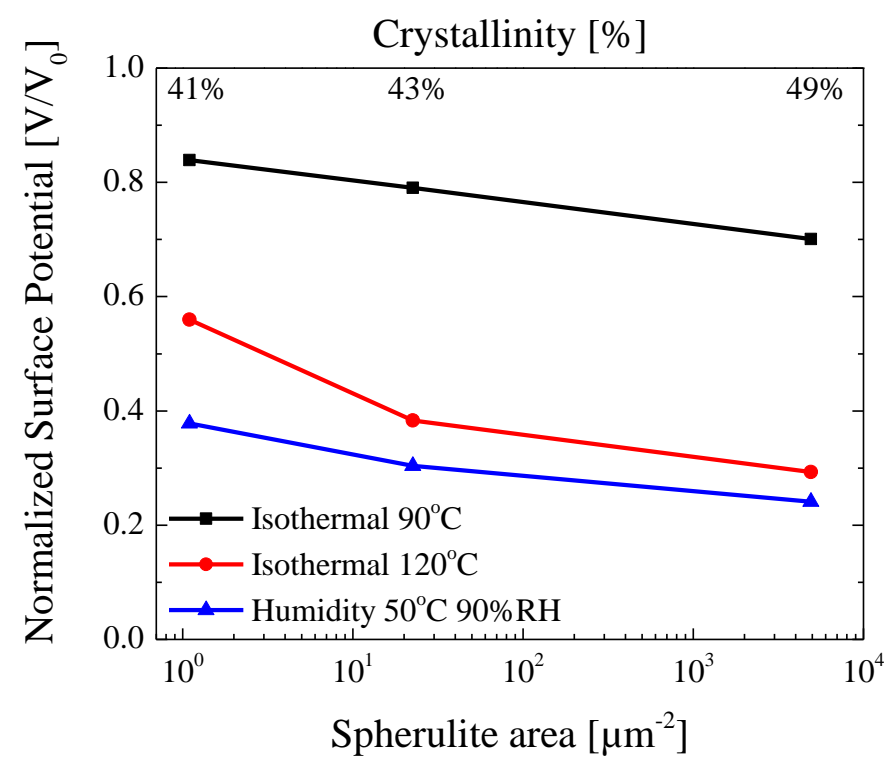

Figure 3.4 The normalized surface potential measured after 25 hours for the isothermal and humidity experiments, plotted against the mean spherulite area. The corresponding crystallinity for the different cooling methods is also displayed.

\subsection{Thermal and Humidity Stability}

Figure 3.2 shows the decay of the normalized surface potential at isothermal conditions at $90{ }^{\circ} \mathrm{C}$ (solid lines) and $120^{\circ} \mathrm{C}$ (dashed lines) for 25 hours. The general trend is that the faster the samples have been cooled, the better the charge retention is. This effect is more prominent at $120^{\circ} \mathrm{C}$ than at $41 \%$ $90{ }^{\circ} \mathrm{C}$. The better charge retention at faster cooling rates correlates well with what others have reported. In [13] they used $\sim 50 \mu \mathrm{m}$ thick isotactic polypropylene samples that were compressed from a $1.1 \mathrm{~mm}$ thick injection molded sample. The

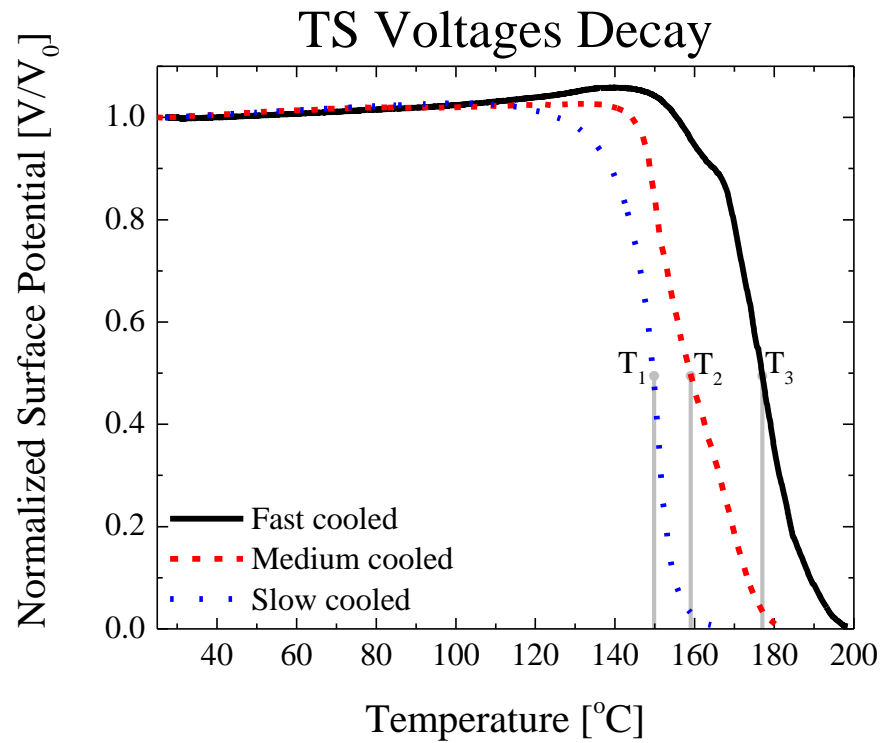

Figure 3.5 The normalized surface potential for the thermally stimulated voltage discharge experiments. It is seen that the charge retention is better for samples that have experienced a fast cooling form its liquid state, supporting the findings in Figure 3.2, 3.3 and 3.4. $\mathrm{T}_{1}, \mathrm{~T}_{2}$ and $\mathrm{T}_{3}$ indicate the critical charge release temperature, which is $150{ }^{\circ} \mathrm{C}, 159^{\circ} \mathrm{C}$ and $177^{\circ} \mathrm{C}$ respectively.

letters in Figure 3.2 indicate different cooling rates (calculated within [13] from $260^{\circ} \mathrm{C}$ to $110^{\circ} \mathrm{C}$ ): $\mathrm{B}=10 \mathrm{~K} / \mathrm{min}, \mathrm{C}=10 \mathrm{~K} / \mathrm{min}$, $\mathrm{D}=235 \mathrm{~K} / \mathrm{min}$ and $\mathrm{E}=300 \mathrm{~K} / \mathrm{min}$.

Comparing our results with [14], where they have used biaxially stretched isotactic polypropylene with a thickness of $\sim 50 \mu \mathrm{m}$, it is seen that the improvement in charge retention from quenching the samples is comparable with the charge retention gained from air voids within polypropylene. The cooling rate in [14] is, however, not stated.

Figure 3.3 shows the decay of the normalized surface potential at $50{ }^{\circ} \mathrm{C}$ and $90 \% \mathrm{RH}$. The trend of better charge retention for samples that have been exposed to the highest cooling rate, can be seen again. However, the charge retention at $50{ }^{\circ} \mathrm{C}$ and $90 \% \mathrm{RH}$ is lower than at isothermal condition at $120^{\circ} \mathrm{C}$. This suggests that the exposure to water vapor is more critical for charge retention than temperature, when looking at what can be expected at normal ambient conditions.

In Figure 3.4, the normalized surface potential after 25 hours for the isothermal and humidity experiments is plotted against the mean spherulite area, listed in Table 3.1. The corresponding crystallinity for the different cooling methods is also displayed. Here it is seen that there is a correlation between the area of the spherulites and the charge retention. Again, it is seen that the charge retention at $50{ }^{\circ} \mathrm{C}$ and $90 \% \mathrm{RH}$ is worse than at isothermal conditions at $120^{\circ} \mathrm{C}$. It is seen that the samples with the lowest crystallinity has the best stability.

Figure 3.5 shows the normalized surface potential for the thermally stimulated voltage discharge experiments. Here it is clearly seen that, the charge retention is better for samples that have been treated with the highest cooling rate, supporting the findings in Figure 3.2, Figure 3.3 and Figure 3.4. In Figure 3.5 the critical charge release temperature, for the different cooling methods, has been indicated as $\mathrm{T}_{1}, \mathrm{~T}_{2}$ and $\mathrm{T}_{3}$ which is at $150^{\circ} \mathrm{C}$, $159^{\circ} \mathrm{C}$ and $177^{\circ} \mathrm{C}$ respectively. We have defined the critical 
charge release temperature as the temperature where the initial surface potential has decayed to $50 \%$ under a constant heat rate. What is seen is that the critical charge release temperature is increased from $150{ }^{\circ} \mathrm{C}$ for the slowly cooled samples to $177^{\circ} \mathrm{C}$ for the fast cooled samples. What also is seen in Figure 3.5 is that the normalized surface potential increases to above 1.0 before it rapidly discharges. This can partially be explained as thermal expansion of polypropylene, however, it cannot explain the entire increment. The fact that the normalized surface potential increases to above 1.0 can be seen as the samples being very stable, until their individually critical charge release temperature is reached.

The obtained charge stability, observed with a high cooling rate, presented in Figure 3.2 to Figure 3.5, is a combined effect of the increased number of spherulites and the decrease in the size of the spherulites. The decrease in the crystallinity does not dominate the stability. In [1] it is demonstrated how the deep charge traps are located at the center of the spherulites and the shallow traps are located at the boundaries and the peripheral regions of the spherulites. The increased charge stability has happened in spite of the decrease in crystallinity. A decrease in crystallinity will counteract the combined effect of the increased number of spherulites and the decrease in the size of the spherulites. Even though it would be excepted that a decrease in crystallinity would have a negative effect on the charge stability, this is not seen due to the dominating effect from the increased number of spherulites and the decrease in the size of the spherulites.

\section{Conclusion}

In the presented work, we conclude that smaller and increased number of spherulites give better charge retention in polypropylene. We have demonstrated that there is a correlation between increased charge stability, with respect to temperature and humidity, and a combination of a decrease in the size of the spherulites and an increased number of spherulites.

The size of the spherulites has been controlled through cooling from polypropylenes liquid state to its solid state. The control through cooling was chosen to eliminate the influence from any nucleating agents. For the samples that have been cooled the fastest, the size of the spherulites were too small to be seen in an optical microscope and they were instead visualized using SEM. The mean area of the spherulites that have been cooled the fastest was 3 orders of magnitude smaller than the area of the spherulites that had been slowly cooled, going from $1 \mu \mathrm{m}^{2}$ to $2950 \mu \mathrm{m}^{2}$ respectively.

The crystallinity for the fast cooled samples was $41 \%$ and $49 \%$ for the slowly cooled samples. Even though it is excepted that a decrease in crystallinity will have a negative effect on the charge stability, this is not seen due to the dominating effect from the increased number of spherulites and the decrease in the size of the spherulites.

The fast cooled samples exhibited significantly improved charge stability in comparison with the slowly cooled samples. After 25 hours in the isothermal experiments at $90{ }^{\circ} \mathrm{C}$ the charge retention increased from $70 \%$ of the initial surface potential in the slowly cooled samples to $84 \%$ in the fast cooled samples. For the isothermal experiments at $120{ }^{\circ} \mathrm{C}$ the corresponding numbers are $26 \%$ and $56 \%$ for the slowly and fast cooled samples, respectively. Similarly for the humidity experiments the numbers are $24 \%$ and $37 \%$ for the slowly and fast cooled samples, respectively.

The effect of the higher cooling rate is also seen in the thermal stimulated voltage decay as a high cooling rate resulted in an increased critical charge release temperature, from $150{ }^{\circ} \mathrm{C}$ for the slowly cooled samples to $177{ }^{\circ} \mathrm{C}$ for the fast cooled samples.

This work has also shown that the preparation of electret samples is of utmost importance when looking at their charge stability. It is therefore extremely important to know these parameters and, how and why they affect the charge stability.

\section{References}

[1] A. Yagishita, K. Ikezaki, and H. Yamanouchi, "Charge trapping sites in spherulitic polypropylene," Japanese J. Appl. Physics, Part 1 Regul. Pap. Short Notes Rev. Pap., vol. 38, no. 4A, pp. 2053 2058, 1999.

[2] D. Libster, A. Aserin, and N. Garti, "Advanced nucleating agents for polypropylene," Polym. Adv. Technol., vol. 18, no. 9, pp. 685695, Sep. 2007

[3] M. Dong, Z. Guo, Z. Su, and J. Yu, "Study of the crystallization behaviors of isotactic polypropylene with sodium benzoate as a specific versatile nucleating agent," J. Polym. Sci. Part B Polym. Phys., vol. 46, no. 12, pp. 1183-1192, Jun. 2008.

[4] G.-S. Jang, W.-J. Cho, and C.-S. Ha, "Crystallization behavior of polypropylene with or without sodium benzoate as a nucleating agent," J. Polym. Sci. Part B Polym. Phys., vol. 39, no. 10, pp. 1001-1016, May 2001.

[5] F. J. Padden and H. D. Keith, "Spherulitic Crystallization in Polypropylene," J. Appl. Phys., vol. 30, no. 10, pp. 1479-1484, 1959.

[6] J. Varga and J. Karger-Kocsis, "Rules of supermolecular structure formation in sheared isotactic polypropylene melts," J. Polym. Sci. Part B Polym. Phys., vol. 34, no. 4, pp. 657-670, 1996.

[7] D. Norton and A. Keller, "The spherulitic and lamellar morphology of melt-crystallized isotactic polypropylene," Polymer (Guildf)., vol. 26, pp. 704-716, 1985.

[8] M. Aboulfaraj, B. Ulrich, A. Dahoun, and C. G'Sell, "Spherulitic morphology of isotactic polypropylene investigated by scanning electron microscopy," Polymer (Guildf)., vol. 34, no. 23, pp. 48174825, Jan. 1993.

[9] J. Park, K. Eom, O. Kwon, and S. Woo, "Chemical Etching Technique for the Investigation of Melt-crystallized Isotactic Polypropylene Spherulite and Lamellar Morphology by Scanning Electron Microscopy," Microsc. Microanal., vol. 7, no. 03, pp. 276286, Feb. 2002.

[10] C. C. Ibeh, Thermoplastic materials : properties, manufacturing methods, and applications. 2011.

[11] J. A. Giacometti and O. N. Oliveira, "Corona charging of polymers," IEEE Trans. Electr. Insul., vol. 27, no. 5, pp. 924-943, 1992.

[12] M. Iijima and G. Strobl, "Isothermal crystallization and melting of isotactic polypropylene analyzed by time- and temperaturedependent small-angle X-ray scattering experiments," Macromolecules, vol. 33, pp. 5204-5214, 2000.

[13] N. Mohmeyer, N. Behrendt, X. Zhang, P. Smith, V. Altstädt, G. M. Sessler, and H.-W. Schmidt, "Additives to improve the electret properties of isotactic polypropylene," Polymer (Guildf)., vol. 48, no. 6, pp. 1612-1619, Mar. 2007.

[14] J. Hillenbrand, N. Behrendt, V. Altstädt, H.-W. Schmidt, and G. M. Sessler, "Electret properties of biaxially stretched polypropylene films containing various additives," J. Phys. D. Appl. Phys., vol. 39, no. 3, pp. 535-540, Feb. 2006. 


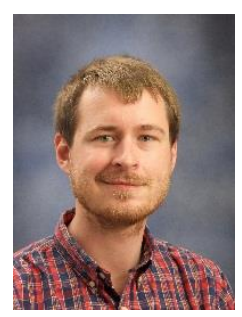

A. Thyssen was born in Toftlund, Denmark in 1986. He received the B.Sc. and M.Sc degree from the Technical University of Denmark, Kgs. Lyngby, Denmark in 2010 and 2012. He is currently a Ph.D. student at the Technical University of Denmark at the department of Micro and Nanotechnology.

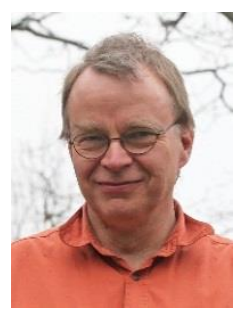

K. Almdal (born in Frederiksberg, Denmark 1958). $\mathrm{He}$ received his M.Sc. and Ph.D. for the University of Copenhagen in 1985 and 1989. His research interests include polymer synthesis, polymer physics, polymer degradation and self-organization phenomena in particular in block copolymers. He is currently professor in polymers in micro- and nanotechnology at the Technical University of Denmark in Kgs. Lyngby. He is elected member of the Danish Academy of Natural Sciences and Danish Academy of Technical Science.

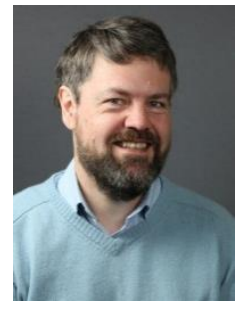

E. V. Thomsen was born in Aarhus, Denmark, in 1964. He received the M.Sc. degree in physics from Odense University, Odense, Denmark, and the Ph.D. degree in electrical engineering from the Technical University of Denmark (DTU),Kgs. Lyngby, in 1998. He has been affiliated with the Department for Micro and Nanotechnology, DTU, since 1992. He is group leader for the MEMS Applied Sensors Group. His current research and teaching interests include Electret based devices, MEMS multisensors; bio-medical devices; small scale energy systems, such as miniature fuel cells and energy harvesting devices; capacitive micromachined ultrasonic transducers; and piezoelectric MEMS. He teaches classes in solid-state electronics, microtechnology, and nano- and microfabrication. Dr. Thomsen received the AEG Electron Prize in 1995 and has received several teaching awards at DTU. 